\title{
STENT-GRAFT ENTRY CLOSURE AND BALLOON FENESTRATION FOR A CASE OF AORTIC DISSECTION ACCOMPANIED BY ORGAN MALPERFUSION
}

Taro Shimazaki, MD, Shin Ishimaru, MD, Satoshi Kawaguchi, MD, Yoshihiko Yokoi, MD, and Yoshiko Watanabe, MD, Tokyo, Japan

The advantages of stent-graft entry closure for aortic dissection were introduced by the Stanford group. ${ }^{1}$ Stent-graft placement is expected to be a promising treatment for acute aortic dissection. The purpose is to seal a primary entry by endovascular stentgrafting, thereby decompressing the false lumen and leading to thrombosis in the false lumen. However, in the case of renal or mesenteric artery malperfusion from a false lumen, stent-graft entry closure might result in ischemic organ failure caused by thrombosis of the false lumen. We report on a case of aortic dissection associated with renal and mesenteric artery malperfusion

From the Department of Surgery II, Tokyo Medical University, Tokyo, Japan.

J Thorac Cardiovasc Surg 2001;121:1216-8

Copyright () 2001 by The American Association for Thoracic Surgery

$0022-5223 / 2001 \$ 35.00+0 \quad \mathbf{1 2 / 5 4 / 1 1 2 4 7 2}$

doi: $10.1067 / \mathrm{mtc} .2001 .112472$ that was treated successfully by stent-graft entry closure and balloon fenestration to secure kidney and intestinal blood flow.

Clinical summary. A 42-year-old man with a chronic Stanford type B dissection was a candidate for stent-graft treatment. A primary entry site was detected at the proximal descending thoracic aorta. The superior mesenteric artery and left renal artery could not be delineated by preoperative angiograms of the true lumen, which indicated that they were perfused from the false lumen (Fig 1). After informed consent was obtained, the endovascular procedure was performed in the operating room with the patient under general anesthesia. An intravascular ultrasonic (IVUS) catheter (6F, 12.5 Mz, Sonicath; Boston Scientific Co, Boston, Mass) was introduced via the right femoral artery into the aorta. On the contralateral femoral artery, a $5 \mathrm{~F}$ pigtail catheter (Cook Group Incorporated, Bloomington, Ind) was introduced over a 0.035-inch stiff guide wire (Amplatz Super Stiff; Boston Scientific Co). Under IVUS monitoring 


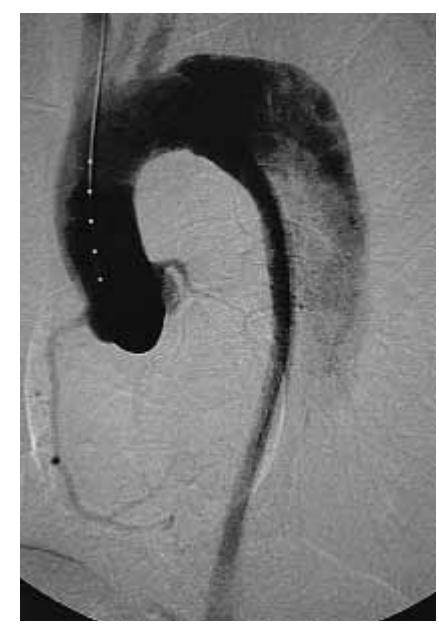

A

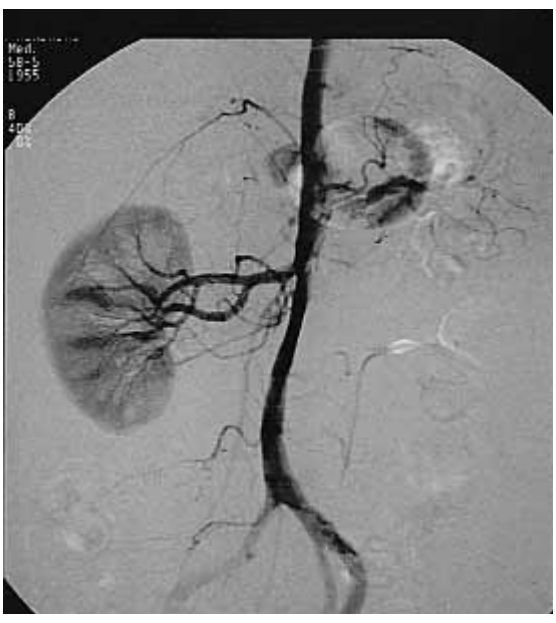

B

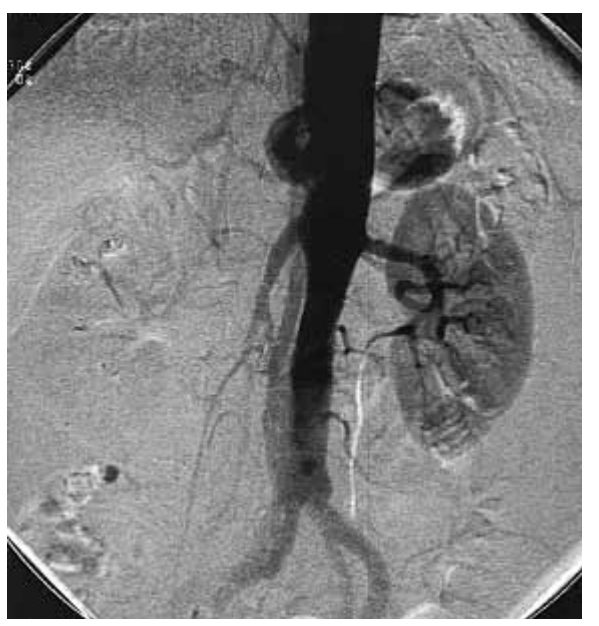

C

Fig 1. Digital subtraction angiography shows that the false lumen involved the superior mesenteric artery and the left renal artery. A and B, Angiograms from the true lumen. C, Angiogram from the false lumen.

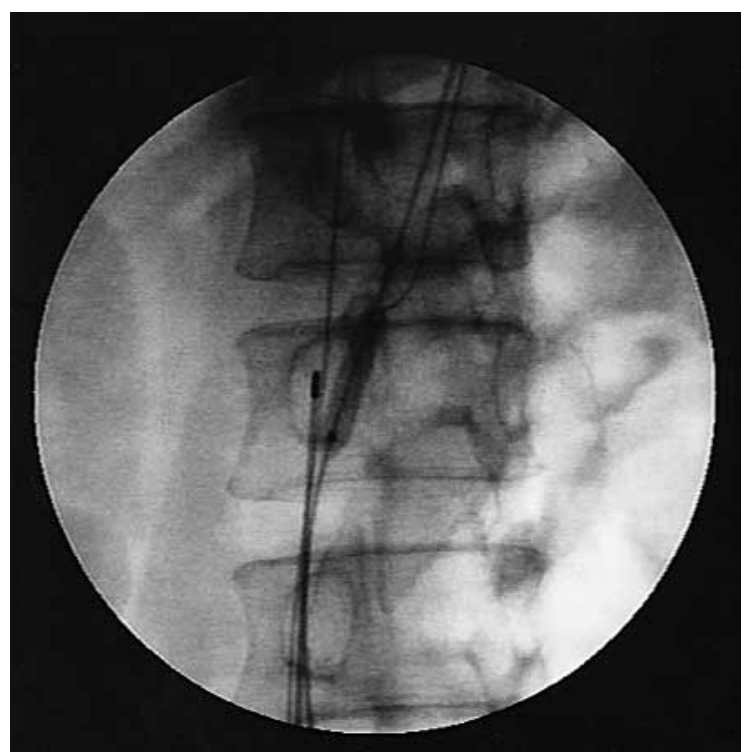

Fig 2. An angioplasty balloon catheter positioned across the intimal flap.

and fluoroscopic guidance, a guide wire was passed through the intimal flap into the false lumen.

The right femoral artery was exposed. Three thousands units of heparin sodium was administered intravenously and activated coagulation time was kept over 200 seconds. A 400$\mathrm{cm}$ 0.032-inch guide wire was introduced through the right brachial artery and threaded down to the abdominal aorta. The distal end of the guide wire was caught with a snare catheter (Amplatz goose-neck snare; Microvena Co, WhiteBear Lake, Minn) and picked up at the femoral artery. A 20F sheath (Keller Timmerman Sheath; Cook Group In-

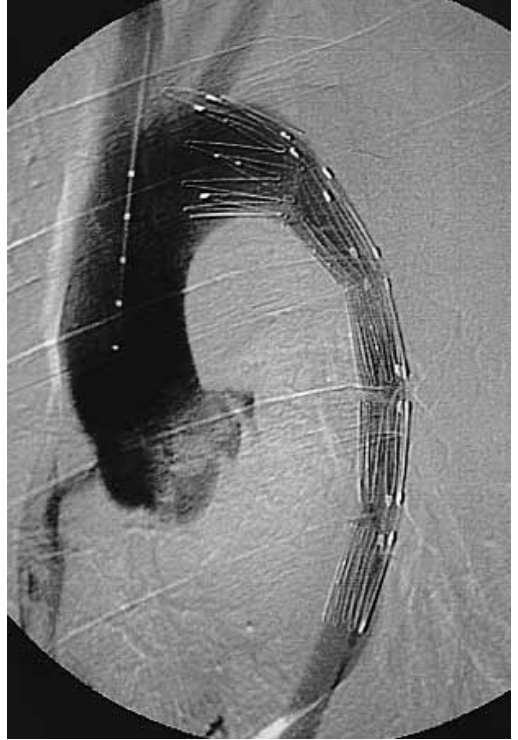

Fig 3. Postoperative angiogram revealed that the stent-graft closed the entry of the false lumen.

corporated) was introduced transfemorally over the guide wire with the tug-of-wire technique. ${ }^{2}$ The stent-graft was constructed from a self-expanding Gianturco Z stent (Cook Group Incorporated) and thin-wall woven polyester fabric (Ube woven-graft; Ube Industries, Inc, Ube, Japan). The proximal diameter of the stent-graft was $36 \mathrm{~mm}$ and the distal diameter was $28 \mathrm{~mm}$. The length of the stent-graft was 180 $\mathrm{mm}$. The stent-graft was delivered through the sheath and sealed the primary entry.

Flow of contrast material from the true lumen to the superior mesenteric artery was not detected by digital subtraction 


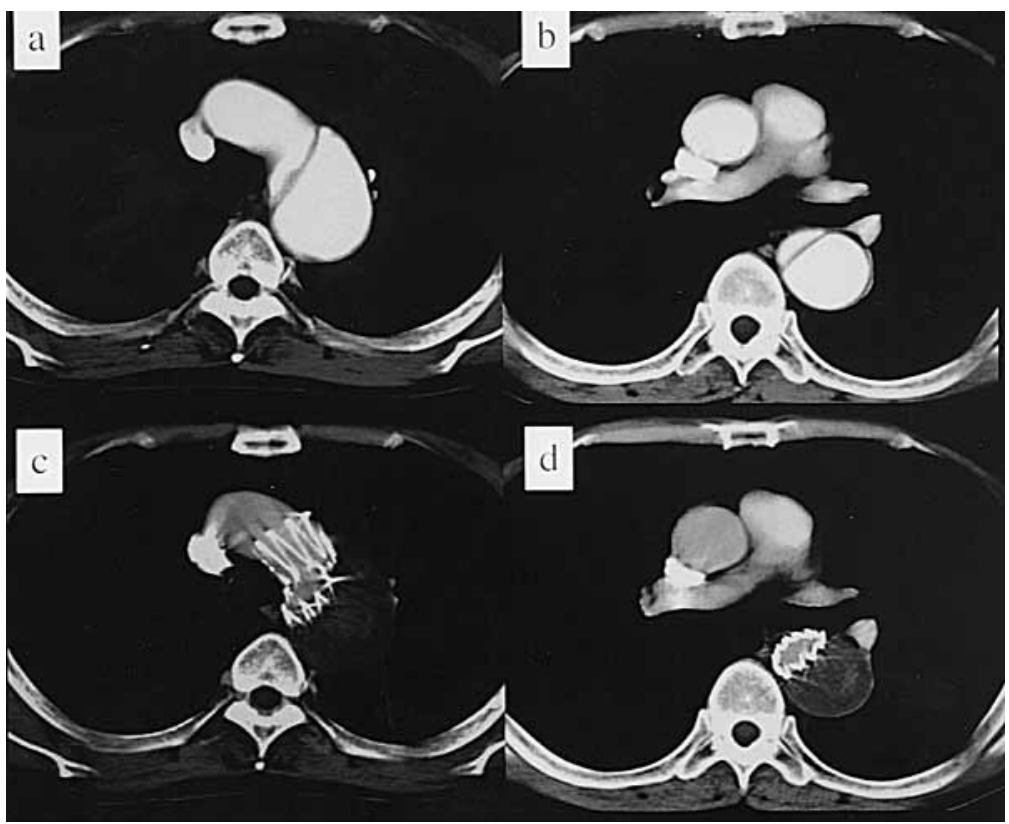

Fig 4. Preoperative (a) and (b) and postoperative (c) and (d) computed tomograms show thrombosis of the thoracic aortic false lumen by the stent-graft treatment.

angiography (Fig 1, B). We thought that fenestration by means of balloon was necessary to preserve the blood flow to the intestine. A balloon catheter with a balloon diameter of 10 $\mathrm{mm}$ (Boston Scientific Co) was advanced over the guide wire from the true lumen to the false lumen and positioned across the intimal flap (Fig 2). A postprocedural digital subtraction angiogram indicated flow to the false lumen through the new entry we had created.

The postoperative course was uneventful without renal failure or ischemic colitis. The patient was discharged 14 days after stent-graft treatment. Postoperative angiography revealed that the entry of the false lumen was closed by the stent-graft (Fig 3). A computed tomographic scan showed partial thrombosis of the false lumen 3 months after the operation (Fig 4).

Discussion. The purpose of stent-graft replacement is to seal the intimal tear and decompress the false lumen. Stent-graft placement is expected to be less invasive than standard open surgery. It is difficult to estimate the amount of thrombus that has formed in the false lumen, because there are many variations of entry and re-entry localizations in each case. Intestinal or leg ischemia and renal failure are all possible complications when the renal or mesenteric arteries are perfused from the false lumen. Particularly in these cases, stent-graft entry closure and balloon fenestration seem to be ideal methods of therapy.

We performed balloon fenestration under IVUS observation. The location of the dissected flap and guide wire could be easily visualized by IVUS monitoring.

Slonim and associates ${ }^{3}$ reported that false lumen obliteration was successfully treated with endovascular stent place- ment and balloon fenestration for aortic dissection. In our experience, stent-graft entry closure after balloon fenestration is a less invasive endovascular treatment in the case of type B dissection associated with organ malperfusion. In this case, we used a 10-mm balloon to effect the fenestration. Further investigation will be necessary to determine the optimal balloon size.

Received for publication Oct 12, 2000; accepted for publication Oct 23, 2000.

Address for reprints: Taro Shimazaki, MD, Department of Surgery II, Tokyo Medical University, 6-7-1, Nishishinjuku, Shinjuku-ku, Tokyo 160-0023, Japan (E-mail: taroshi@pa2.so-net.ne.jp).

\section{REFERENCES}

1. Dake MD, Kato N, Mitchell RS, Semba CP, Razavi MK, Shimono T, et al. Endovascular stent-graft placement for the treatment of acute aortic dissection. $\mathrm{N}$ Engl $\mathrm{J}$ Med 1999;340:1546-52.

2. Ishimaru S, Kawaguchi S, Koizumi N, Obitsu Y, Ishikawa M. Preliminary report on prediction of spinal cord ischemia in endovascular stent graft repair of thoracic aortic aneurysm by retrievable stent graft. J Thorac Cardiovasc Surg 1998;115:811-8.

3. Slonim SM, Miller DC, Mitchell RS, Semba CP, Razavi MK, Dake MD. Percutaneous balloon fenestration and stenting for life-threatening ischemic complications in patients with acute aortic dissection. J Thorac Cardiovasc Surg 1999;117:1118-27. 